Disponível em

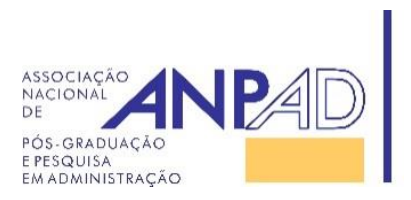

http://www.anpad.org.br/rac

RAC, Rio de Janeiro, v. 20, n. 5, art. 5, pp. 610-629, Set./Out. 2016

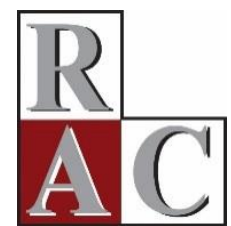

(c) $) \mathrm{EY}$

\title{
Comportamento Materialista em Adolescentes e Crianças: Uma Meta-análise dos Antecedentes e dos Consequentes
}

Materialistic Behavior in Adolescents and Children: A Meta-analysis of the Antecedents and Consequents

Wagner Junior Ladeira ${ }^{1}$ Fernando de Oliveira Santini ${ }^{1}$

Clecio Falcão Araujo ${ }^{2}$

Universidade do Vale do Rio dos Sinos ${ }^{1}$ Pontifícia Universidade Católica do Rio Grande do Sul ${ }^{2}$

Artigo recebido em 08.06.2015. Última versão recebida em 03.10.2015. Aprovado em 10.10.2015. Publicado online em 17.03.2016. 


\title{
Resumo
}

O presente artigo propõe uma meta-análise dos antecedentes e dos consequentes do comportamento materialista entre crianças e adolescentes. Foram identificados 42 estudos científicos localizados em cinco bases de dados, os quais geraram 53 effect sizes, envolvendo uma amostra acumulada de 9.283 crianças e adolescentes. Foi proposto um modelo teórico hipotetizado com base em quatro antecedentes, quatro consequentes e três variáveis moderadoras. Os resultados demonstraram uma relação direta e significativa entre o comportamento materialista de crianças e adolescentes, e, na grande parte das variáveis, antecedentes e consequentes. Ademais, observou-se que a satisfação com a vida apresentou relação negativa com o comportamento materialista. Em relação aos efeitos moderadores, confirmou-se que o local da aplicação da pesquisa tem uma influência significativa sobre a magnitude dos effect sizes. Quanto ao efeito moderador do tamanho da amostra e do país da amostra, estes não exercem influência sobre a magnitude dos efeitos. Além dos resultados destacados, ressalta-se a contribuição teórica proporcionada por esta meta-análise no sentido de prover uma revisão teórica consistente que resultou na integração quantitativa dos principais construtos relacionados aos antecedentes e consequentes do comportamento materialista em crianças e adolescentes.

Palavras-chave: comportamento materialista; materialismo; antecedentes; consequentes; moderadores.

\begin{abstract}
This paper proposes a meta-analysis of antecedents and consequences of materialistic behavior among children and adolescents. We detected 42 studies, selected from five databases, which generated 53 effect sizes involving an aggregate sample of 9,283 children and adolescents. We proposed a theoretical model based on four antecedents, four consequents and three moderating variables. The results showed a direct and significant relation between materialistic behavior by children and adolescents in most of the antecedent and consequent variables. Furthermore, we found that life satisfaction held a negative relation with materialistic behavior. As for the moderating effects, we confirmed that survey location has a significant influence on effect sizes. Regarding the moderating effect of the sample size and country of application, they do not exert influence on the effect size. In addition to its outcomes, this meta-analysis offers a remarkable theoretical contribution, which provides a consistent theoretical review that resulted in the quantitative integration of the main constructs associated with the antecedents and consequents of materialistic behavior in children and adolescents.
\end{abstract}

Key words: materialistic behavior; materialism; antecedents; consequents; moderators. 


\section{Introdução}

As primeiras fases da vida, compreendidas entre as etapas da infância e da adolescência, são especialmente importantes na formação da personalidade de um indivíduo, uma vez que as experiências obtidas durante esses ciclos tendem a repercutir num padrão de comportamento replicado ao longo da existência (Ward, 1974). Isso se torna ainda mais relevante quando se observa a vulnerabilidade de personalidade, característica dessas etapas (Tsang, Carpenter, Roberts, Frisch, \& Carlisle, 2014) e expressa no comportamento de constante (re)afirmação de identidade, busca de pertencimento social e até mesmo de status e poder (Johnson \& Attmann, 2009; Tsang et al., 2014). Por outro lado, surge o materialismo, que tem sido utilizado como um construto para buscar explicações sobre essas representações simbólicas dentro de um espectro de comportamento (Belk, 1985; Goldberg, Gorn, Peracchio, \& Bamossy, 2003).

O conceito de materialismo foi disseminado a partir do estudo seminal de Belk (1985), que propôs sua ligação com o comportamento consumista e a posse de bens. Nessa lógica, os consumidores materialistas necessitam, para ter felicidade, de bens materiais e dinheiro (Richins \& Chaplin, 2015), uma vez que consideram a posse como tendo um papel decisivo em suas vidas, norteador da satisfação ou insatisfação pessoal (Watson, 2003). Dentre as características mais marcantes do materialismo, está a busca pela autoidentidade, que se dá a partir do desejo de aceitação pelos outros (Baker, Moschis, Benmoyal-Bouzaglo, \& Santos, 2013), fato bastante característico nas fases de infância e adolescência, quando se busca uma consolidação da personalidade (Yang, De Wang, \& Niu, 2008).

A partir dessas associações, nos últimos anos houve um aumento substancial de pesquisas que buscaram estudar o comportamento materialista entre crianças e adolescentes (Wray-Lake, Flanagan, \& Osgood, 2010). Isso pode ser comprovado pelo número de artigos publicados acerca desse tema em diversos journals de marketing e de áreas correlatas como a psicologia social, pois esse assunto se vincula diretamente com traços de personalidade e comportamentos psicossociais (O'Guinn \& Faber, 1989; Santos \& Fernandes, 2011). Pesquisando-se em cinco bases de dados diferentes, foram encontrados 42 artigos que estudavam o materialismo entre adolescentes e crianças. Desses, grande parte foi publicada a partir de 2000 .

Apesar do número crescente de trabalhos, persistem questões na literatura acadêmica que ainda merecem uma reflexão. É o caso dos antecedentes e consequentes do materialismo. Prova disso pode ser observada no antecedente influência interpessoal que, por vezes, apresenta uma relação negativa (Wan et al., 2009), e, em outras, positiva (Fitzmaurice \& Comegys, 2006) ou neutra (BenmoyalBouzaglo \& Moschis, 2010) com esse comportamento. O mesmo vale para construtos consequentes com o materialismo, como é o caso da compra compulsiva, para a qual se podem encontrar tanto pesquisas que demonstram relações positivas (Weaver, Moschis, \& Davis, 2011) como negativas (Richins \& Dawson, 1992).

Dessa forma, faz-se necessária uma consolidação do entendimento sobre antecedentes e consequentes do comportamento materialista, conforme se apresentam nos diversos estudos da área de marketing. Nesse sentido, realizou-se uma revisão sistemática que proporcionou uma pesquisa metaanalítica. Essa última permitiu condensar os resultados das investigações no que tange aos antecedentes e aos consequentes do materialismo com referência ao comportamento de crianças e adolescentes, possibilitando a generalização do tema (Fern \& Monroe, 1996). Como consequência, possibilitou o avanço desse conhecimento (Farley, Lehmann, \& Sawyer, 1995), especialmente pelo fato de as conclusões obtidas através dessa metodologia permitirem definir padrões para o que é considerado estado da ciência, o que sabemos e o que não sabemos, e qual teoria é válida ou qual não é (Schmidt, 1996).

Para alcançar esse objetivo, em um primeiro momento, o artigo discute teoricamente o construto materialismo e suas possíveis relações com o comportamento de crianças e adolescentes. Ainda nessa etapa, discutem-se teoricamente os possíveis moderadores metodológicos dessas relações. Logo após, descreve-se o processo de coleta de dados empíricos para a realização da meta-análise, seguindo-se a 
interpretação e a análise dos resultados. Por fim, são feitas as considerações finais pautadas nas contribuições acadêmicas e mercadológicas desse estudo, também enfocando suas limitações e sugestões de pesquisas futuras.

\section{O Comportamento Materialista na Fase Inicial da Vida e sua Mensuração}

Dentro da literatura de comportamento do consumidor, de um modo geral, o materialismo é visto como a importância que o indivíduo dá a uma aquisição como centro de conquista em sua vida (Richins \& Chaplin, 2015). Nesse sentido, o materialismo é visto sob três aspectos: (a) uma tendência a julgar o próprio sucesso e o de outros a partir da posse material; (b) a crença de que a aquisição leva à felicidade; e (c) a aquisição como centro da vida.

A investigação desse fenômeno tem sido realizada essencialmente por pesquisas quantitativas que, em sua grande maioria, utilizam as escalas desenvolvidas por Belk (1985) e por Richins e Dawson (1992). No âmbito das fases de infância e adolescência, especial atenção é dada a esse assunto, a tal ponto que Goldberg, Gorn, Peracchio e Bamossy (2003), desenvolveram a escala denominada de Youth Materialism Scale (YMS), que atualmente tem sido objeto de aplicação e discussão (Vega \& Roberts, 2011).

A razão desse interesse é que os indivíduos, a partir das fases iniciais da vida, começam a desenvolver a necessidade primária de satisfação de um desejo. Nesse estágio, o materialismo é visto como um valor emergente centrado na ganância (Goldberg et al., 2003). Segundo os autores, isso inclui o desejo de comprar as próprias coisas, o gozo relacionado a essas aquisições e, até mesmo, a ambição por profissões que irão assegurar a possibilidade de atingir essas compras.

Diante disso, dá-se importância a estudar o materialismo no âmbito da infância e da adolescência com base na aquisição de bens materiais. Sendo esses estágios da vida caracterizados pela busca incessante de aceitação social, a inexperiência e as dúvidas sobre a própria identidade são apontadas como as causas principais da imersão no comportamento materialista (Belk, 1991; Richins, 2004; Richins \& Chaplin, 2015). Nessa lógica, pesquisas realizadas apontam um comportamento materialista mais forte em indivíduos jovens do que em adultos (Park, Rabolt, \& Jeon, 2008).

\section{Antecedentes do comportamento materialista em crianças e adolescentes}

Com base na análise das principais escalas que mensuram o materialismo (Belk, 1985; Goldberg et al., 2003; Richins \& Dawson, 1992), buscaram-se estudos em bases de dados que evidenciassem os principais antecedentes do comportamento materialista em adolescentes e crianças, desde que esses estudos possuíssem, no mínimo, três observações por construto, conforme é exigido por Hedges e Olkin (1985) para a realização de estudos meta-analíticos. Após essa análise, foram observados quatro construtos que serão hipotetizados e discutidos no modelo teórico: influência interpessoal, satisfação com a vida, sexo feminino e idade.

O primeiro antecedente refere-se à influência interpessoal. Nos estudos de marketing e psicologia, esse antecedente vincula-se a uma necessidade de identificação com um grupo, seja ela normativa ou informacional, procurando melhorar a própria imagem (Kropp, Lavack, \& Silvera, 2005). A busca por essa aceitação pode-se expressar na aquisição e na utilização de produtos de marcas (Bearden, Netemeyer, \& Teel, 1989), sendo, nesse caso, bastante vinculada ao comportamento materialista, já que o sentimento de posse é um dos subterfúgios para inserção e aceitação de um indivíduo perante uma comunidade (Baker et al., 2013).

No âmbito investigado, as crianças e as adolescentes aprendem que os valores de consumo são aceitáveis aos olhos dos outros, sendo que essas informações servem como normas sociais (Chan \& 
Prendergast, 2007). Pesquisas aplicadas junto a crianças e adolescentes consolidam essa suposição (Baker et al., 2013; Chia, 2010). Assim, supõe-se que:

$\mathbf{H}_{1}$ : A influência interpessoal se relaciona positivamente com o comportamento materialista em crianças e adolescentes.

O segundo construto analisado é a satisfação com a vida, que foi relacionada ao comportamento materialista no momento em que pesquisas seminais da área como, por exemplo, as realizadas por Belk (1985) e Richins e Dawson (1992), apontaram associações negativas entre os dois comportamentos. Reforçando essa suposição, Kasser, Ryan, Zax e Sameroff (1995) detectaram associações entre materialismo e altos níveis de depressão. Outras pesquisas consolidam essas suposições ratificando as percepções propostas, ou seja, a relação negativa entre a satisfação com a vida e o comportamento materialista (Tsang et al., 2014).

O estudo de Goldberg et al. (2003) detectou que crianças e adolescentes com comportamento materialista são menos engajadas em responsabilidades escolares e mais preocupadas com os comportamentos de compra. Ademais, encontram-se também relações positivas entre o comportamento materialista e o aumento do risco de transtornos psicológicos (Cohen \& Cohen, 1996). A partir disso, sugere-se que:

$\mathbf{H}_{2}$ : A satisfação com a vida relaciona-se negativamente com o comportamento materialista em crianças e adolescentes.

O terceiro construto é pautado no sexo da criança ou do adolescente. As diferenças detectadas entre os comportamentos de homens e mulheres têm sido de grande valia para fins acadêmicos e práticos nas estratégias de segmentação de mercado. Essa linha de investigação ganha corpo com estudos como os realizados por Kempf, Laczniak e Smith (2006), Kruger e Byker (2009) e, ainda, Liao, Shen e Chu (2009). O primeiro destaca que as pessoas do sexo feminino são mais detalhistas ao processar as informações de publicidade de produtos. O segundo afirma que as mulheres são mais receptivas a promoções. O último detecta que as mulheres são mais impulsivas do que os homens.

Por outro lado, e reforçando essa suposição, crianças e adolescentes do sexo masculino são mais propensos a realizar compras planejadas (Buttle, 1992), enquanto que as do sexo feminino sentem a atividade de compra como algo mais prazeroso (Santos \& Fernandes, 2011). Essas suposições ficam ainda mais evidentes quando se encontra, no estudo de Santos e Fernandes (2011) e, mais recentemente, no de Rindfleisch, Burroughs e Wong (2009), uma relação significativa entre adolescentes do sexo feminino e o comportamento materialista. Dessa forma, é possível supor que o sexo feminino deverá apresentar comportamentos materialistas mais fortes. Então, supõe-se que:

$\mathbf{H}_{3}$ : O sexo feminino relaciona-se positivamente com o comportamento materialista em crianças e adolescentes.

A idade, nessa pesquisa, constitui o último antecedente do comportamento materialista. Quanto à relação da idade com o comportamento materialista, há duas linhas de interpretação. Uma, formada por autores mais antigos, dá conta de que consumidores, com o passar dos anos, têm mais maturidade e contato com o processo de compra e, como consequência, menor predisposição para o comportamento materialista (Belk, 1985). A segunda linha de interpretação, composta por autores contemporâneos, não supõe essa relação, sugerindo que tanto consumidores jovens como adultos têm o mesmo acesso a informações como, por exemplo, a internet, o que tende a diminuir as diferenças de comportamento entre esses grupos nas experiências de compras (Goldberg et al., 2003).

Esta pesquisa é pautada no entendimento de que as fases da infância e da adolescência são circundadas pela busca da autoidentidade e da aceitação (Yang et al., 2008). Dessa forma, supõe-se uma relação positiva entre a menor idade e o comportamento materialista. Salienta-se que a separação dos dados teve como parâmetro um relatório publicado pelo Fundo das Nações Unidas para a Infância (2015) em que crianças estão compreendidas entre as idades de 1 a 9 anos e adolescentes de 10 a 19 anos. A 
média de idade dos estudos aplicados em crianças e utilizados nessa pesquisa foi de 8,17 e, em adolescentes, 14,54. Assim, supõe-se que:

$\mathbf{H}_{4}$ : Quanto menor for a idade da criança ou do adolescente, maior será o comportamento materialista.

\section{Consequentes do comportamento materialista em crianças e adolescentes}

Além dos antecedentes, esta pesquisa também coletou informações acerca dos principais consequentes do comportamento materialista em crianças e adolescentes. Foram detectados quatro construtos a partir da revisão sistemática realizada: intenção de compra, compra compulsiva, comportamento de status e envolvimento.

O primeiro consequente é a intenção de compra do consumidor. Pressupõe-se que esse construto esteja diretamente relacionado ao comportamento materialista, uma vez que o preceito básico do mesmo está nos sentimentos de aquisição e posse (Belk, 1985). Diante disso, são inúmeros os contextos nos quais é possível observar a relação positiva entre o comportamento materialista e a intenção de compra. No âmbito estudado, pode-se citar como exemplo pesquisas que encontram associações entre o comportamento materialista e a compra de jogos eletrônicos (Chang \& Zhang, 2008), CDs (Wan et al., 2009) e roupas (Handa \& Khare, 2013). Ademais, estudos realizados nos mais diversos países, como é o caso do Brasil (Gil, Kwon, Good, \& Johnson, 2012), da Índia (Handa \& Khare, 2013), dos Estados Unidos (Kim \& Jang, 2014) e da China (Chan, Zhang, \& Wang, 2006), entre outros, dão ainda mais consistência aos resultados. Dessa forma, sugere-se que:

$\mathbf{H}_{5}$ : O comportamento materialista em crianças e adolescentes relaciona-se positivamente com a intenção de compra do consumidor.

O segundo construto diz respeito à compra compulsiva. É importante salientar que, na esfera do materialismo, a investigação da compra compulsiva tem perspectivas variadas. Por exemplo, algumas pesquisas dão explicações psicológicas, afirmando que a compra serve para lidar com situações desagradáveis da vida (Weaver et al., 2011), como o divórcio dos pais (Roberts, Manolis, \& Tanner, 2006). Por outro lado, alguns estudos a relacionam a um processo de socialização, como é o caso do estudo de Neuner, Raab e Reisch (2005), cuja pesquisa demonstra que a queda do muro de Berlim acarretou o aumento da compra compulsiva por parte dos alemães orientais que viviam, até então, sob o regime socialista. Encontram-se, ainda, alguns estudos na área que sugerem uma visão mais humanista. Neste caso, a compra compulsiva é decorrente de uma dificuldade de formar uma autoimagem, o que pode estar atrelado à autoestima (Roberts \& Pirog, 2004). É importante salientar, ainda, que este conceito, por vezes, é confundido com o de consumo compulsivo, embora sejam noções distintas. Enquanto a compra compulsiva está relacionada à aquisição de bens além do que o indivíduo necessita, o consumo compulsivo diz respeito à utilização exacerbada de um produto (Veludo-de-Oliveira, Ikeda, $\&$ Santos, 2004).

Neste estudo, adota-se como guia o conceito de O'Guinn e Faber (1989), que definem a compra compulsiva como uma tendência de compra de forma repetitiva e crônica, a qual pode ser desencadeada por eventos como, por exemplo, estímulo do ambiente, ou por sentimentos negativos do indivíduo, fatores estes similares aos que afetam o comportamento materialista (Fitzmaurice \& Comegys, 2006). Além disso, Rindfleisch, Burroughs e Denton (1997) apontam que a compra compulsiva, vinculada ao materialismo, enraíza-se, de forma parcial, nos primeiros anos de desenvolvimento de uma pessoa. Essa observação é reforçada por resultados de pesquisas que encontram associações positivas entre os dois comportamentos (por exemplo, Baker et al., 2013). A partir disso, supõe-se que:

$\mathbf{H}_{6}$ : O comportamento materialista em crianças e adolescentes relaciona-se positivamente com a compra compulsiva.

O comportamento de status é o terceiro consequente presente no modelo hipotetizado e caracteriza-se pela compra de produtos ou serviços com o objetivo de promover uma identificação 
individual (O'Cass \& McEwen, 2004) e, por vezes, chamar a atenção de outros (Goldsmith, Moore, \& Beaudoin, 1999). Alinhado a isso, o comportamento materialista está vinculado ao acúmulo de aquisições de produtos e serviços que vai além de uma necessidade básica, e está pautado na importância de passar uma imagem de sofisticação aos outros (Kasser \& Ahuvia, 2002). Dando ainda mais sentido à relação entre os dois comportamentos, crianças e adolescentes sentem necessidade de se autoafirmarem e a compra de bens sofisticados é a porta de entrada para esse sentimento (Grotts \& Johnson, 2013).

Nesse aspecto, resultados encontrados em vários estudos reforçam essas suposições, sendo possível apontar relações positivas e significativas entre o comportamento materialista e o consumo de status na aquisição de produtos sofisticados (Goldsmith \& Clark, 2012; Grotts \& Johnson, 2013). Assim, sugere-se que:

$\mathbf{H}_{7}$ : $\mathrm{O}$ comportamento materialista em crianças e adolescentes se relaciona positivamente com o consumo de status.

O último consequente avaliado é o envolvimento do consumidor. Esse construto está associado ao grau de interesse ou importância demonstrado em relação a um bem (Handa \& Khare, 2013). São características desse comportamento, assim como do materialismo, o prazer e o entusiasmo atrelados a uma atividade de compra (Belk, 1985; Richins, 2004). A relação entre ambos os construtos fica mais evidente a partir dos resultados apresentados por Browne e Kaldenberg (1997), os quais demonstram existir uma vinculação positiva entre altos graus de comportamento materialista e o envolvimento com produtos que transmitem significados para outros. Além disso, e dentro do âmbito estudado, encontramse pesquisas que ratificam esse achado (Browne \& Kaldenberg; 1997; Handa \& Khare, 2013). Dessa forma, considera-se que:

H8: O comportamento materialista em crianças e adolescentes relaciona-se positivamente com o envolvimento do consumidor.

\section{Moderadores metodológicos da meta-análise}

No total, segundo dados preliminares da meta-análise, três equações foram examinadas teoricamente, no sentido de verificar as variáveis metodológicas que poderiam moderar as relações existentes entre antecedentes e consequentes do comportamento materialista: local da pesquisa (laboratório $v s$. campo), tamanho da amostra (pequena vs. grande) e país da amostra (ocidente $v s$. oriente).

O primeiro moderador metodológico pesquisado nos artigos foi o local da pesquisa. Essa variável foi classificada dicotomicamente como de laboratório ou de campo/real. Os estudos de laboratório caracterizam-se pela criação, por parte do pesquisador, de condições desejadas (cenários) para testes. Nesses casos, é possível observar o efeito da manipulação das variáveis independentes sobre as dependentes, enquanto que os efeitos de outros fatores (variáveis estranhas) são minimizados (Churchill, 1999). Porém, em uma pesquisa de campo/real, dificilmente o pesquisador tem controle sobre as variáveis estranhas (Churchill, 1999), o que justifica o menor poder de explicação dos effect sizes (Fern \& Monroe, 1996). A partir dessa constatação, supõe-se que:

H9a: A relação entre o comportamento materialista em crianças e adolescentes e seus antecedentes/consequentes é mais forte (fraca) para estudos de laboratórios (campo/real).

A variável tamanho da amostra foi testada como a segunda moderadora e foi classificada como grande ou pequena. Essa separação se deu pelo método de percentil, utilizando-se do software SPSS 18. $0^{\circledR}$. Existe um entendimento, exposto por autores consagrados como, por exemplo, Hedges e Olkin (1985) e Rosenthal (1995), de que pequenas amostras produzem effect sizes mais fortes, uma vez que superestimam o referido efeito. Assim sendo, é possível declarar que a magnitude de um efeito pode variar de acordo com o tamanho da amostra (Fern \& Monroe, 1996). Desse modo, supõe-se que: 
H9b: A relação entre o comportamento materialista em crianças e adolescentes e seus antecedentes/consequentes é mais forte (fraca) para estudos com amostras menores (maiores).

Por fim, o último moderador a ser testado foi o país da amostra. Estudos mencionam que, dependendo da cultura dos respondentes da amostra (países ocidentais ou orientais), pode-se ter diferença substancial com relação aos conceitos de individualismo, coletivismo, independência, autonomia, atributos pessoais, orientação do comportamento, entre outros (Hofstede, 1994). Segundo esse raciocínio, é consenso que a cultura oriental é mais direcionada para o coletivismo; nela, os indivíduos se enxergam como grupo, prevalecendo a busca pelo bem-estar de todos (Gudykunst, 1993). Já na cultura ocidental, as pessoas são mais propensas ao individualismo, havendo predomínio de imediatismo, autonomia e independência (Hofstede, 1994). Dessa forma, pode-se supor que, em culturas orientais (coletivistas), os indivíduos sejam menos materialistas. Por sua vez, respondentes de culturas ocidentais tenderiam a apresentar características materialistas mais fortes, uma vez que o individualismo é uma das características evidentes do construto estudado (Belk, 1985; Richins \& Dawson, 1992). Sendo assim, supõe-se que:

H9c: A relação entre o comportamento materialista em crianças e adolescentes e seus antecedentes/consequentes é mais forte (fraca) para estudos realizados em países do ocidente (oriente).

Uma vez discutidas e apresentadas as hipóteses do estudo, a Figura 1 apresenta o modelo teórico a ser testado, contendo os construtos antecedentes e consequentes do comportamento materialista, além das variáveis moderadoras investigadas nesta pesquisa.

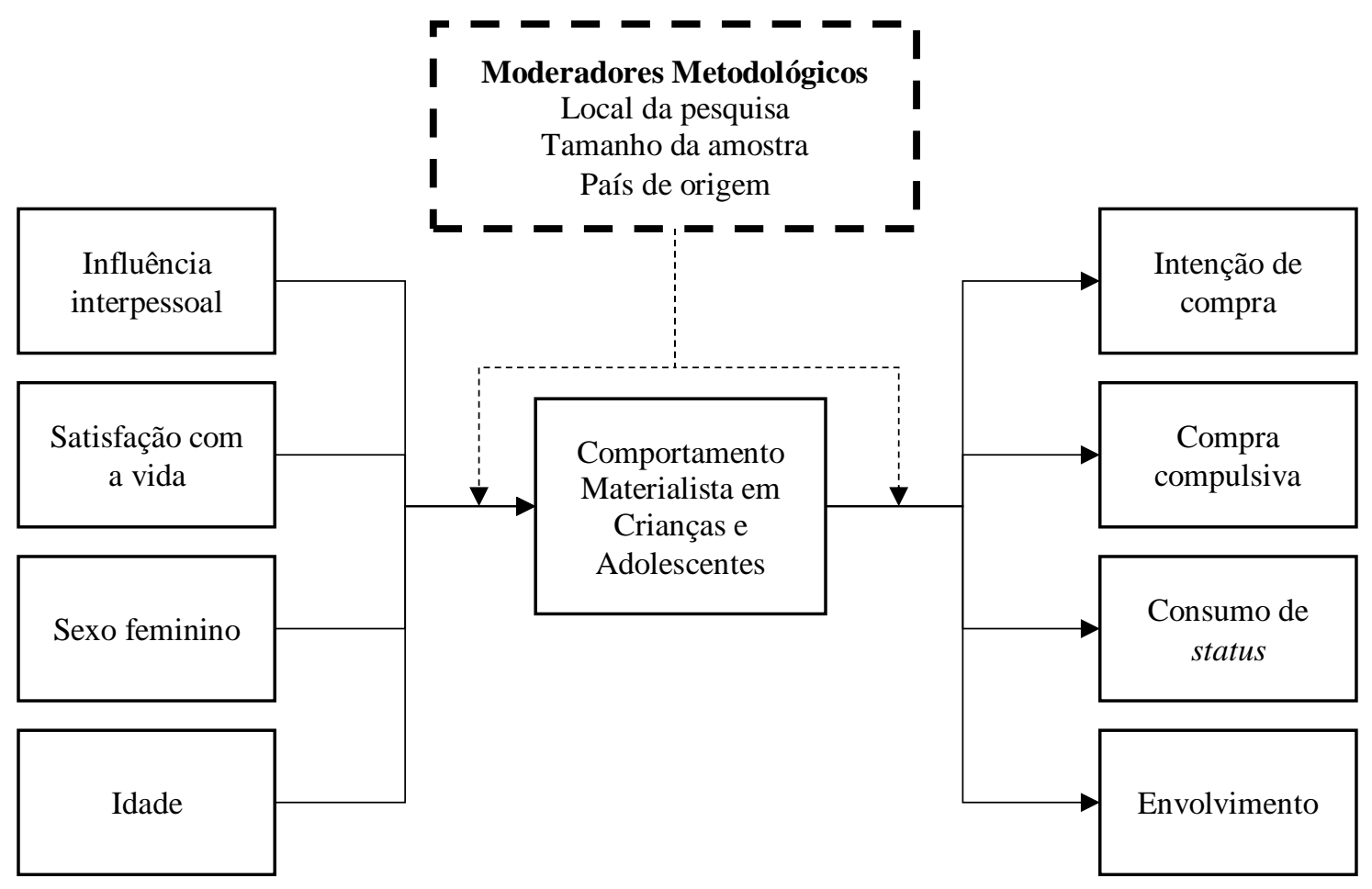

Figura 1. Modelo Hipotetizado a Ser Testado na Meta-Análise

Sintetizando, e conforme anteriormente apresentado, espera-se uma relação positiva e significativa dos antecedentes influência interpessoal e sexo feminino com o comportamento materialista; relação significativa e negativa entre satisfação com a vida e a idade e o comportamento materialista. Quanto aos consequentes, supõem-se relações positivas entre materialismo e intenção de compra, compra compulsiva, consumo de status e envolvimento. Supõe-se, ainda, que estudos realizados em laboratório, com pequenas amostras e em países ocidentais, possam moderar positivamente essas relações. Nesse sentido, o estudo prossegue apresentando a metodologia utilizada para analisar as referidas suposições. 


\section{Procedimentos Metodológicos}

Para realizar o teste das hipóteses, o presente trabalho dividiu os procedimentos metodológicos em quatro etapas. Na Figura 2, são apresentadas as etapas com suas descrições e os principais resultados encontrados.

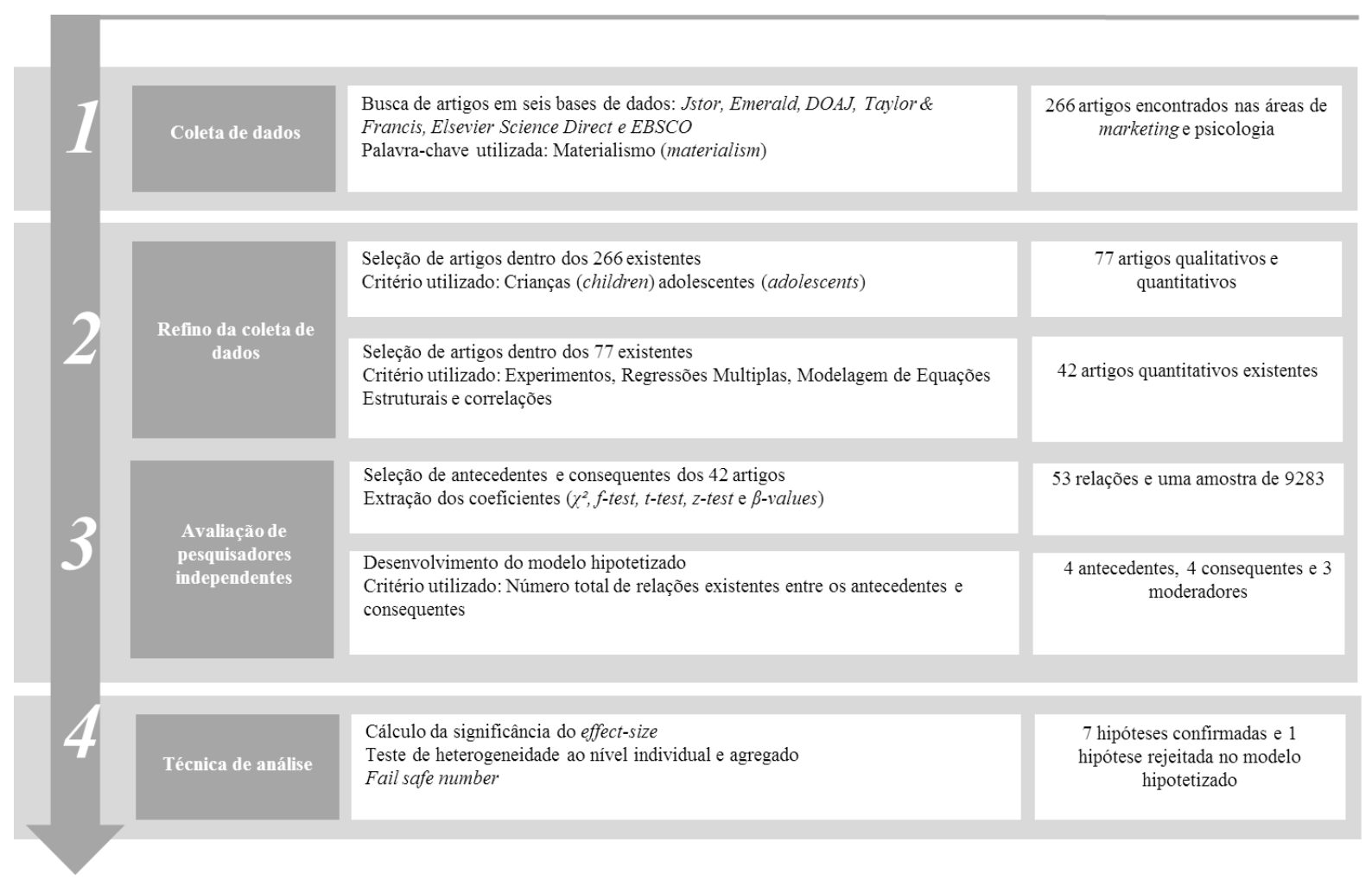

Figura 2. Procedimentos Metodológicos da Meta-análise

Com o intuito de identificar os estudos relevantes para a construção desta meta-análise, empregou-se uma pesquisa bibliográfica em cinco bases de dados científicas (Jstor, Emerald, Taylor \& Francis, Elsevier Science Direct e EBSCO), usando a priori os termos materialismo e materialism, seguidos de children e adolescents. Para isso, consideraram-se trabalhos científicos disponíveis em três idiomas: espanhol, inglês e português. Após essa etapa, foram selecionados 266 trabalhos científicos que utilizavam o termo materialismo.

Logo após essa coleta inicial, foi feita uma catalogação desses artigos, selecionando os que eram aplicados em pesquisas com crianças e adolescentes. No total foram selecionados 77 artigos. A principal relação de interesse pesquisada nessa etapa foi a de possíveis antecedentes e consequentes do materialismo. Por isso, foram selecionados 42 artigos quantitativos para análise, sendo que, desses, 10 eram estudos provenientes da Psicologia Social e 32 do marketing. Nesse conjunto de artigos, foram encontradas 53 correlações, que resultaram numa amostra acumulada de 9.283 indivíduos. Desse total, $79 \%$ das pesquisas foram aplicadas junto a estudantes, $67 \%$ realizadas em ambiente artificial, e $64 \%$ em países ocidentais. Destaca-se, também, o predomínio (48\%) da utilização da escala de Richins e Dawson (1992) para mensuração do comportamento materialista.

A codificação dos dados foi realizada por dois pesquisadores da área de marketing, sendo que cada artigo foi analisado por um único avaliador. Antes do início dessa atividade, os critérios de análise foram amplamente discutidos entre os autores deste estudo. Além disso, para os casos de artigos que geraram dúvidas na extração dos dados (5\%), realizaram-se reuniões com a participação dos dois avaliadores e de um terceiro autor, que serviu como juiz. 
Foram identificadas, nessa etapa, quatro variáveis antecedentes (influência interpessoal, satisfação com a vida, sexo feminino e idade), quatro consequentes (intenção de compra, compra compulsiva, consumo de status e envolvimento) e três variáveis moderadoras (local da pesquisa, tamanho da amostra e país da amostra).

Quanto à análise de dados, utilizou-se o coeficiente de correlação $r$ de Pearson como variável métrica para mensurar o tamanho do efeito sobre as variáveis do escopo estudado. Para os estudos que não relataram a correlação $r$, as estatísticas apresentadas, como, $\chi^{2}, \mathrm{f}$-test, $\mathrm{t}$-test, $\mathrm{z}$-test e $\beta$-values foram convertidas em coeficiente de correlação, procedimento esse recomendado por Hedges e Olkin (1985). Utilizou-se o método sugerido por Hunter e Schmidt (2004) em relação à análise do efeito randômico de effect-size, sendo os effect-sizes corrigidos pelo tamanho da amostra e pelos índices de confiabilidade das escalas utilizadas.

\section{Interpretação e Análise dos Resultados}

Inicialmente, ressalta-se que foram objetos de análise 42 trabalhos, sendo que esses foram publicados entre os anos de 1997 a 2014. Observa-se uma concentração de mais da metade dos trabalhos publicados (23) na última década, fato que reforça a importância da realização desse estudo. Tomandose os índices de Alpha de Cronbach do construto materialismo, detecta-se uma média de 0,79, variando de 0,57 a 0,90 . Não foi observada uma correlação entre o ano de publicação e o tamanho de amostra.

A Tabela 1 apresenta a síntese dos resultados obtidos na meta-análise. Os efeitos presentes nos artigos analisados, como apontamos antes, foram transformados em correlação produto-momento de Pearson, $r$.

Tabela 1

Síntese dos Resultados da Meta-análise

\begin{tabular}{|c|c|c|c|c|c|c|c|c|c|c|}
\hline Relações & $(\mathbf{k})(\mathbf{o})$ & & $\mathbf{N}$ & $\mathbf{M}_{\mathbf{N} \omega}$ & Sig 1 & $\begin{array}{c}\text { ICI } \\
(\mathbf{9 5 \%})\end{array}$ & $\begin{array}{c}\text { ICS } \\
(\mathbf{9 5 \%})\end{array}$ & $\mathbf{Q}$ & $\mathrm{Sig}_{2}$ & FSN \\
\hline \multicolumn{11}{|l|}{ Antecedentes } \\
\hline Influência interpessoal & 6 & 8 & 1456 & 0,236 & 0,003 & 0,12 & 0,36 & 29,4 & 0,000 & 8 \\
\hline Satisfação com a vida & 3 & 3 & 1452 & $-0,286$ & 0,002 & $-0,37$ & $-0,20$ & 0,2 & 0,278 & 1 \\
\hline Sexo feminino & 7 & 8 & 3729 & 0,117 & 0,000 & 0,18 & 0,06 & 19,0 & 0,007 & 12 \\
\hline Idade & 8 & 9 & 5911 & 0,018 & 0,129 & $-0,05$ & 0,08 & 40,1 & 0,000 & $\mathrm{NC}$ \\
\hline \multicolumn{11}{|l|}{ Consequentes } \\
\hline Intenção de compra & 5 & 5 & 1774 & 0,385 & 0,000 & 0,30 & 0,47 & 9,6 & 0,040 & 4 \\
\hline Compra compulsiva & 9 & 9 & 2059 & 0,374 & 0,000 & 0,16 & 0,58 & 159,7 & 0,000 & 6 \\
\hline Consumo de status & 4 & 7 & 2048 & 0,506 & 0,000 & 0,27 & 0,73 & 203,6 & 0,000 & 10 \\
\hline Envolvimento & 4 & 4 & 1156 & 0,709 & 0,000 & 0,59 & 0,77 & 3,9 & 0,270 & 4 \\
\hline
\end{tabular}

Nota. Fonte: Elaborados pelos autores com base nos resultados da pesquisa.

$\mathrm{k}=$ número de estudos utilizados para análise; $\mathrm{o}=$ número de observações extraídas dos estudos para análise; $\mathrm{N}=$ número de amostras acumuladas dos estudos avaliados; $\mathrm{M}_{\mathrm{N} \alpha}=$ média do efeito ponderada e corrigida a partir da amostra e alpha obtido nos estudos; $\mathrm{Sig}_{1}$ = grau de significância do effect size ; ICI = intervalo de confiança inferior; ICS = intervalo de confiança superior; $Q=$ teste de heterogeneidade ao nível individual e agregado; Sig $_{2}=$ grau de significância do Q; FSN (fail safe number) $=$ número de artigos necessários para o resultado ser falso; $\mathrm{NC}=$ Não calculado, pois effect size foi não significativo $(p>0,05)$. 


\section{Antecedentes e consequentes do comportamento materialista}

Com o intuito de entender melhor as relações entre os antecedentes e os consequentes do comportamento materialista em crianças e adolescentes, faz-se necessário conhecer os índices gerados na análise de dados. $\mathrm{Na}$ hipótese $\mathrm{H}_{1}$, era prevista uma relação positiva entre a influência interpessoal e o comportamento materialista. Essa suposição tinha como amparo teórico o estudo de Belk (1982), o qual dá conta de que crianças e adolescentes, por vivenciarem constantemente situações de incertezas, tenderiam a ser mais suscetíveis à influência de outros na compra materialista, pois isso proporcionaria a aceitação por um grupo (Bearden et al., 1989). Os resultados foram obtidos através da análise de seis estudos e oito observações. Os dados apontam uma relação significativa, positiva e com força $r=0,236$ $(p<0,01)$. Além disso, o número de trabalhos com resultados nulos ou contrários suficientes para rejeitar o achado (fail safe number) é de oito. Esses dados levam à confirmação da suposição prevista na hipótese $\mathrm{H}_{1}$.

A segunda hipótese $\left(\mathrm{H}_{2}\right)$ previa uma relação negativa entre a satisfação com a vida e o comportamento materialista. Isso porque estudos como os realizados por Cohen e Cohen (1996), Goldberg et al. (2003) e Froh, Emmons, Card, Bono e Wilson (2011) ratificam a suposta relação no contexto investigado. Nesse sentido, a primeira pesquisa detectou que jovens com comportamento materialista possuem maiores chances de apresentar transtornos psicológicos. A segunda observou problemas escolares em crianças e adolescentes com características materialistas. Na última, foi possível observar relações com a dificuldade de integração social. Os resultados observados na tabela 1 apontaram uma relação significativa e negativa com força de $r=-0,286(p<0,01)$, conforme esperado. Assim, confirmou-se a hipótese $\mathrm{H}_{2} \mathrm{O}$ fail safe number encontrado foi de apenas um estudo, ou seja, bastante frágil em função do pequeno número de artigos identificados na coleta de dados. Isso faz supor que os comportamentos materialistas em crianças e adolescentes podem trazer como consequência transtornos de ordem psicológica como, por exemplo, níveis de depressão (Kasser \& Ryan, 1993).

O fator sexo foi objeto de investigação da terceira hipótese $\left(\mathrm{H}_{3}\right)$. A proposição era que jovens do sexo feminino apresentariam relações materialistas mais fortes. Isso porque, dentro do ambiente de marketing, existe a suposição de que as mulheres, de uma forma geral, são bastante suscetíveis a receber informações de publicidade sobre produtos ou serviços (Kempf, Laczniak, \& Smith, 2006) e são muito receptivas a promoções (Kruger \& Byker, 2009), além de apresentarem mais características impulsivas em comparação aos homens (Liao, Shen, \& Chu, 2009). Além disso, e reforçando o previsto, Buttle (1992) apresentou pesquisa na qual ratificou a maior probabilidade da realização de compras não planejadas para jovens do sexo feminino. Os índices apresentaram uma relação positiva, significativa e com força $r=0,117$ ( $p<0,001$ ), sendo que o fail safe number foi de 12 estudos. Com esses dados, confirma-se a hipótese $\mathrm{H}_{3}$, ou seja, é possível afirmar que existe uma relação positiva entre crianças e adolescentes do sexo feminino e o comportamento materialista.

Por fim, a última hipótese proposta, no âmbito de antecedentes $\left(\mathrm{H}_{4}\right)$, sugeria uma relação negativa entre a idade das crianças e adolescentes e o comportamento materialista. Teoricamente, era esperada essa relação, pois, quanto menor a idade, maior seria a inexperiência com compras e a necessidade de autoafirmação e aceitação perante os outros (Yang et al., 2008). Sendo assim, a proposta era que, como resultado das inseguranças e da falta de experiência na atividade de compras, prevaleceria o comportamento materialista (Belk, 1985). Pelo resultado levantado em nove observações, não foi possível detectar essa relação $(r=0,018 ; p=0,129)$, rejeitando-se, assim, a hipótese $\mathrm{H}_{4}$. A não comprovação do achado dá mais força para a linha teórica que sustenta cada vez menos diferença entre as idades para níveis de experiência de compra. Isso porque as mídias e a internet proporcionaram um nivelamento do acesso às informações entre as pessoas (Santos \& Fernandes, 2011).

$\mathrm{Na}$ hipótese $\mathrm{H}_{5}$, era suposta uma relação significativa e positiva entre o comportamento materialista e a intenção de compra do consumidor. Isso porque as duas condutas estão intimamente ligadas, pois o preceito básico do comportamento materialista está pautado no sentimento de aquisição e posse (Belk, 1985), fato esse consagrado no contexto de comportamentos de crianças e adolescentes (Chang \& Zhang, 2008; Handa \& Khare, 2013; Wan et al., 2009). Dentro do escopo de coleta aqui relatado, encontraram-se cinco estudos que avaliaram as referidas relações. O resultado demonstra 
relações positivas e significativas entre os dois comportamentos $(r=0,385 ; p<0,001$; fail safe number $=4$ ), o que traz consolidação para as suposições colocadas e, consequente, confirmação da $\mathrm{H}_{5}$.

Seguindo a investigação dos consequentes, chega-se à hipótese $\mathrm{H}_{6}$, que previa uma associação positiva entre o comportamento materialista e a compra compulsiva. Os resultados apresentaram uma força de $r=0,374$ ( $p<0,001$ ). Além disso, detectou-se um fail safe number de seis estudos. A confirmação da hipótese $\mathrm{H}_{6}$ permite ratificar suposições teóricas cujos resultados já apontavam para essa relação (Baker et al., 2013; Joung, 2013), fortalecendo a doutrina de que é possível o desenvolvimento de atividades de compra compulsiva nos primeiros anos de vida (Rindfleisch, Burroughs, \& Denton, 1997) e, como consequência, esse se entrelaça com a necessidade materialista de consumo (Fitzmaurice \& Comegys, 2006).

$\mathrm{Na}$ hipótese $\mathrm{H}_{7}$, esperava-se uma relação positiva e significativa entre o comportamento materialista e o consumo de status. Essa suposição tinha como alicerce o preceito de que a compra de produtos sofisticados seria fomentada pela necessidade de aceitação social, dada a necessidade característica das crianças e adolescentes de autoafirmação (Grotts \& Johnson, 2013) e inserção em grupos (Goldsmith et al., 1999). De acordo com a investigação efetivada, resultante de sete observações, chegou-se à confirmação da hipótese $\mathrm{H}_{7}$, uma vez que a relação encontrada entre os comportamentos foi positiva, significativa e com força $r=0,506(p<0,001)$. Esse dado reforça as teorias que entrelaçam os comportamentos evidenciados no consumo de produtos sofisticados (Goldsmith \& Clark, 2012; Grotts \& Johnson, 2013). O número de trabalhos necessários para rejeitar o achado, ou seja, o fail safe number, é de dez.

A hipótese $\mathrm{H}_{8}$ previa uma relação positiva e significativa entre o comportamento materialista e o envolvimento do consumidor. Justifica-se, teoricamente, essa suposição, na medida em que se percebem comportamentos convergentes entre os dois construtos, como é o caso do entusiasmo e do prazer envolvidos numa atividade de compra (Belk, 1985; Richins, 2004). De acordo com os índices identificados e dispostos na tabela 1, observa-se a confirmação da hipótese, pois a força de correlação foi de $r=0,709$ ( $p<0,001)$. O fail safe number, para esse caso, foi de quatro estudos. Dessa forma, ratificam-se estudos que já encontraram essa relação no âmbito aqui investigado (Handa \& Khare, 2013; Hourigan \& Bougoure, 2012).

\section{Análise dos moderadores metodológicos}

A análise de moderação foi aplicada para as seguintes situações: (a) quando a estatística $Q$, correspondente à heterogeneidade dos effect sizes, mostrava-se superior a 25\% (Hunter \& Schmidt, 2004); (b) quando o número de estudos era igual ou superior a nove, uma vez que números inferiores seriam insuficientes para notar alterações nos comportamentos por meio de moderadores (Hunter \& Schmidt, 2004). Com base nessas justificativas, realizou-se o teste do efeito moderador somente para a relação entre comportamento materialista e compra compulsiva (consequente).

O primeiro efeito moderador testado diz respeito à possível influência do local da aplicação da pesquisa. Para esse caso, foram separados os estudos realizados em laboratório e em campo. Os resultados apresentados $\left(F_{(1,07)}=18,180 ; p<0,005 ;\right.$ poder $=0,953 ; \eta^{2}=72,2 \% ; M_{\text {laboratório }}=0,43 ; M_{\text {campo }}$ $=-0,12$ ) confirmam a hipótese $\mathrm{H}_{9 \mathrm{a}}$ e, assim, reforçam a teoria que sugere a produção de effect sizes mais fortes em estudos de laboratório, pois estes permitem controlar com maior eficiência as variáveis estranhas (Churchill, 1999; Fern \& Monroe, 1996).

Quanto à hipótese $\mathrm{H}_{9 \mathrm{~b}}$, que sugeria um efeito moderador do tamanho da amostra (pequeno vs. grande) sobre a relação entre os comportamentos estudados, os resultados não foram os esperados, pois a diferença de médias entre os dois grupos não foi significativa $\left(F_{(1,07)}=0,352 ; p=0,572\right.$; poder $=0,081$; $\eta^{2}=0,48 \% ; M_{\text {pequena }}=0,39 ; M_{\text {grande }}=0,26$ ). Portanto, não se confirmou a hipótese $H_{9 b}$. Fica o alento, porém, de que, apesar de não ser estatisticamente significante, observou-se uma média de effect sizes maior em estudos com amostras pequenas, conforme proposto na teoria (Fern \& Monroe, 1996). 
Finalizando a análise de possíveis efeitos moderadores, a hipótese $\mathrm{H}_{9 \mathrm{c}}$ previa que estudos aplicados em países do ocidente produziriam effect sizes mais fortes do que estudos realizados em países do oriente, uma vez que culturas individualistas (ocidentais) são mais propensas ao consumo (Hofstede, 1994). A partir do resultado detectado na análise efetivada $\left(F_{(1,07)}=2,304 ; p=0,173\right.$; poder $=0,260 ; \eta^{2}$ $=24,8 \% ; M_{\text {ocidente }}=0,43 ; M_{\text {oriente }}=0,15$ ), não foi possível confirmar a referida suposição, o que nos faz rejeitar a proposição da hipótese $\mathrm{H}_{9 c}$. testadas.

Por fim, a Tabela 2 apresenta a síntese dos achados nesta pesquisa, com base nas hipóteses

Tabela 2

\section{Síntese dos Achados}

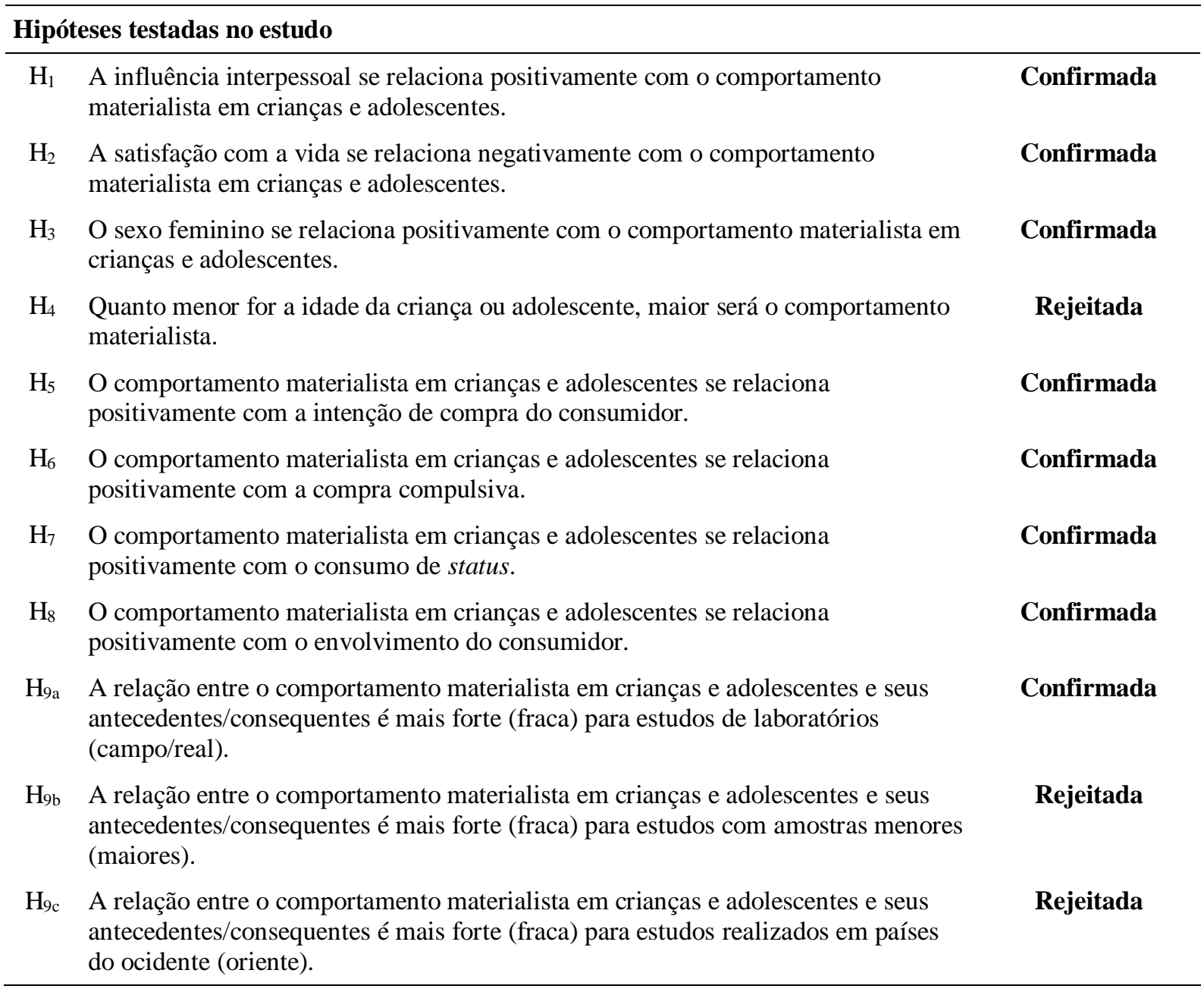

Nota. Fonte: Elaborados pelos autores com base nos resultados da pesquisa.

Observa-se que grande parte das relações diretas antecedentes foi confirmada $\left(\mathrm{H}_{1}, \mathrm{H}_{2}\right.$ e $\left.\mathrm{H}_{3}\right)$, com exceção feita à relação entre idade e comportamento materialista $\left(\mathrm{H}_{4}\right)$. No que tange aos consequentes, o materialismo foi significativo na sua relação com intenção de compra $\left(\mathrm{H}_{5}\right)$, compra compulsiva $\left(\mathrm{H}_{6}\right)$, consumo de status $\left(\mathrm{H}_{7}\right)$ e envolvimento $\left(\mathrm{H}_{8}\right)$. Por fim, encontra-se sustentação estatística para confirmar o efeito moderador do tipo de estudo, demonstrando que pesquisas aplicadas em laboratório tendem e produzir efeitos mais fortes do que pesquisas de campo $\left(\mathrm{H}_{9 \mathrm{a}}\right)$ dentro das relações testadas. 


\section{Considerações Finais}

Esta pesquisa investigou as relações existentes entre o comportamento materialista em crianças e adolescentes e seus principais antecedentes, consequentes e variáveis moderadoras. Para isso, realizouse uma revisão sistemática da literatura existente sobre o tema a partir de cinco bases de dados. Essa revisão possibilitou a extração de dados das pesquisas realizadas e sua consequente meta-análise para atingir os objetivos propostos, a partir de 42 artigos selecionados que geraram uma amostra acumulada de 9.283 entrevistados.

Os resultados revelam que antecedentes como a influência interpessoal e o sexo feminino têm um relacionamento positivo com o materialismo entre crianças e adolescentes. Esse fato reforça a suposição de que crianças e adolescentes vivenciam uma fase circundada de incertezas e inseguranças (Belk, 1982) e, como consequência, são suscetíveis a receber a influência dos outros (Bearden et al., 1989), sendo que as jovens do sexo feminino estão mais propensas a exibir comportamentos materialistas (Kruger \& Byker, 2009).

Em contrapartida, observaram-se também relações negativas do comportamento materialista entre jovens e adolescentes com um possível antecedente, no caso, a satisfação com a vida. Esse fato pode ser sustentado por estudos que afirmam que jovens com propensão a problemas psíquicos e sociais tendem a apresentar maior incidência de características materialistas (Goldberg et al., 2003). Essas afirmações são admissíveis, pois se obteve associação negativa entre a satisfação com a vida e o materialismo.

No âmbito dos estudos que enfatizaram os consequentes, todas as relações foram identificadas como positivas, o que indica que o comportamento materialista pode ser considerado um lenitivo para as dúvidas e as incertezas comumente manifestadas na infância e na adolescência (Belk, 1982), com impactos diretos na compra compulsiva e até mesmo no consumo por status.

No contexto do marketing, é bastante comum notar estudos que investigam o comportamento materialista (Benmoyal-Bouzaglo \& Moschis, 2010), sendo esse caracterizado por desejos de posse e aquisição de bens materiais para o alcance de objetivos da vida ou, simplesmente, estados desejados (Goldberg et al., 2003; Richins, 2004). Além disso, o estudo permitiu consolidar a noção de que consumidores materialistas jovens demonstram relações positivas com a intenção de compra, uma vez que, nessa fase da vida, o sentimento de posse facilita a inserção em grupos (Handa \& Khare, 2013). Ainda assim, por vezes, esse sentimento pode ser decorrente de um impulso incontrolável que resulta em uma compra compulsiva (Joung, 2013), fato preocupante, uma vez que esse comportamento poderá ser gerador de uma patologia já nos primeiros anos da vida (Baker et al., 2013).

Não menos interessantes são as ratificações teóricas resultantes dos achados a respeito da vinculação positiva entre o comportamento materialista e o consumo de status. Tal dado, mais uma vez, pode ser decorrente de uma vocação para a busca de autoafirmação e inserção em grupos (Goldsmith $e t$ al., 1999). Por fim, fica fortalecida a associação entre o comportamento materialista e o envolvimento do consumidor, em vista das relações encontradas, pois tal envolvimento pode estar vinculado ao entusiasmo e ao prazer de uma compra (Belk, 1985; Richins, 2004).

Nosso estudo apoia pesquisas anteriores que sugerem a influência do materialismo sobre crianças e adolescentes. Nossa pesquisa diferencia-se de outros estudos por apresentar um modelo que traz, ao mesmo tempo, antecedentes, consequentes e moderadores do materialismo. Esta investigação ganha ainda mais importância por ser aplicada ao contexto de adolescentes e crianças, um campo que ainda carece de investigação (Roberts et al., 2003; Santos \& Fernandes, 2011) e representa uma parcela significativa dos investimentos aportados em marketing pelas empresas (Bergadaá, 2007).

Além dos resultados destacados, ressalta-se a contribuição teórica proporcionada por esta metaanálise, no sentido de prover uma revisão teórica consistente que resultou na integração quantitativa dos principais construtos relacionados aos antecedentes e aos consequentes do comportamento materialista em crianças e adolescentes. Dessa forma, o presente estudo agrega diferentes evidências empíricas e 
auxilia num entendimento mais compreensivo dos efeitos aqui investigados. Assim sendo, esta metaanálise poderá possibilitar uma melhor compreensão do fenômeno do comportamento materialista e, como consequência, sua melhor mensuração, especialmente por observar que, em alguns casos, não há consenso nos resultados encontrados nas pesquisas realizadas.

Gerentes, no atacado ou no varejo, costumam utilizar estratégias para convencer pais e mães a comprarem produtos ou serviços para seus filhos. Através desta meta-análise, esses profissionais podem aprimorar sua estratégia, incorporando aspectos associados à influência interpessoal, à compulsividade e ao consumo por status. Esta pesquisa também demonstra que aspectos inconscientes, como a satisfação com a vida, podem também ser influenciadores do materialismo. Desse modo, é necessário que os gerentes estudem os fatores contextuais que influenciam o consumo de crianças e adolescentes.

Por outro lado, os resultados aqui encontrados podem remeter a debates interessantes no âmbito social para o estabelecimento de políticas públicas, educacionais e familiares que visem à diminuição de comportamento materialista em crianças e adolescentes. Por exemplo: (a) a restrição da propaganda em canais focados em jovens poderia inibir a influência interpessoal, a intenção de compra, a compra compulsiva e o consumo de status que são desencadeados pelo comportamento materialista?; (b) a restrição de comerciais e endossadores vinculados a esse público seria outra saída?; (c) pais e familiares poderiam ser os agentes de educação para um comportamento menos materialista a partir de exemplos dados desde as primeiras relações com seus filhos?; (d) a inclusão de unidades curriculares de comportamento do consumidor nas escolas traria maior reflexão sobre o tema?; e (e) a implementação de uniformes, por parte das escolas, levaria uma diminuição nas comparações sociais e, consequentemente, a um menor grau de comportamento materialista?

O presente estudo reflete questões fundamentais sobre os efeitos do materialismo em crianças e adolescentes. Salienta-se que esta investigação limitou-se às relações de consumo e aquisição de bens. Assim, as questões não respondidas oferecem caminhos para novas pesquisas. Em primeiro lugar, este estudo levantou uma ampla gama de artigos qualitativos que, devido à especificidade das técnicas utilizadas, não foram empregados na parte de análise. Sugere-se aqui um aprofundamento do estudo desses artigos, talvez utilizando apenas uma revisão sistemática como estratégia metodológica de análise. Em segundo lugar, sugerimos a análise dos artigos que, por não apresentarem mais de três relações, não puderam ser utilizados no modelo. Aqui surgem variáveis que mereceriam uma análise mais detalhada: inovação, propaganda, conspicuidade, satisfação, entre outras.

Outra limitação bastante significativa do trabalho diz respeito à não inclusão de variáveis psicossociais e culturais que poderiam anteceder ou potencializar o comportamento materialista em crianças e adolescentes. É o caso, por exemplo, da estrutura familiar (Santos \& Fernandes, 2011), da composição econômica (Flouri, 1999), da distorção de comportamento (Mueller et al., 2011) e, até mesmo, da orientação cultural (McCracken, 1986). A não investigação deu-se pelo fato de não ter sido encontrado, nas bases de dados incorporadas neste estudo, o número suficiente de resultados de pesquisas para que fosse possível efetivar a meta-análise. Nesse sentido, fica como sugestão a futura incorporação de novas bases de dados para avaliar a possibilidade de análise das variáveis não investigadas aqui.

Destaca-se, também, a não possibilidade de realizar a análise em separado do comportamento materialista no âmbito exclusivo de crianças ou de adolescentes. Isso se deve à grande concentração de estudos vinculados a adolescentes que foram investigados nesta pesquisa. Uma nova coleta que consiga separar os dois grupos sociais seria relevante, pois abriria a possibilidade de gerar novas inferências e apontar diferenças comportamentais associadas ao consumo destes grupos.

Por fim, salienta-se que um dos problemas desse tipo de análise é o recorte de conceitos adversos existentes nos dados secundários utilizados. Portanto, destaca-se que, por se tratar de dados empíricos de diferentes autores, tais dados podem ser adversos. 
Apesar das limitações apresentadas, espera-se que esta meta-análise contribua para um melhor e mais amplo entendimento dos antecedentes e consequentes do comportamento materialista, fomentando novas discussões teóricas a respeito do tema.

\section{Referências}

Baker, A. M., Moschis, G. P., Benmoyal-Bouzaglo, S., \& Santos, C. P. dos (2013). How family resources affect materialism and compulsive buying: a cross-country life course perspective. Cross-Cultural Research, 47(4), 335-362. http://dx.doi.org/10.1177/1069397112473074

Bearden, W. O., Netemeyer, R. G., \& Teel, J. E. (1989). Measurement of consumer susceptibility to interpersonal influence. Journal of Consumer Research, 15(4), 473-481. http://dx.doi.org/10.1086/209186

Belk, R. W. (1982). Acquiring, possessing, and collecting: fundamental processes in consumer behavior. In R. F. Bush \& S. D. Hunt (Eds.), Marketing theory: philosophy of science perspectives (pp. 185190). San Antonio, Texas: Marketing Classics Press.

Belk, R. W. (1985). Materialism: trait aspects of living in the material world. Journal of Consumer Research, 12(3), 265-280. http://dx.doi.org/10.1086/208515

Belk, R. W. (1991). The ineluctable mysteries of possessions. Journal of Social Behavior \& Personality, 6(6), 17-55. Recuperado de http://psycnet.apa.org/psycinfo/1992-01439-001

Benmoyal-Bouzaglo, S., \& Moschis, G. P. (2010). Effects of family structure and socialization on materialism: a life course study in France. The Journal of Marketing Theory and Practice, 18(1), 53-70. http://dx.doi.org/10.2753/MTP1069-6679180104

Bergadaá, M. (2007). Children and business: pluralistic ethics of marketers. Society and Business Review, 2(1), 53-73. http://dx.doi.org/10.1108/17465680710725272

Browne, B. A., \& Kaldenberg, D. O. (1997). Conceptualizing self-monitoring: links to materialism and product involvement. Journal of Consumer Marketing, 14(1), 31-44. http://dx.doi.org/10.1108/07363769710155848

Buttle, F. (1992). Shopping motives constructionist perspective. Service Industries Journal, 12(3), 349367. http://dx.doi.org/10.1080/02642069200000044

Chan, K., \& Prendergast, G. (2007). Materialism and social comparison among adolescents. Social Behavior and Personality: An International Journal, 35(2), 213-228. http://dx.doi.org/10.2224/sbp.2007.35.2.213

Chan, K., Zhang, H., \& Wang, I. (2006). Materialism among adolescents in urban China. Young Consumers, 7(2), 64-77. http://dx.doi.org/10.1108/17473610610701510

Chang, J.-H., \& Zhang, H. (2008). Analyzing online game players: from materialism and motivation to attitude. CyberPsychology \& Behavior, 11(6), 711-714. http://dx.doi.org/10.1089/cpb.2007.0147

Chia, S. C. (2010). How social influence mediates media effects on adolescents' materialism. Communication Research, 37(3), 400-419. http://dx.doi.org/10.1177/0093650210362463

Churchill, G. A., Jr. (1999). Marketing research: methodological foundations. Orlando: The Dryden Press.

Cohen, P., \& Cohen, J. (1996). Life values and adolescent mental health. New Jersey: Psychology Press. 
Farley, J. U., Lehmann, D. R., \& Sawyer, A. (1995). Empirical marketing generalization using metaanalysis. Marketing $\quad$ Science, $\quad$ 14(3_supplement), G36G46. http://dx.doi.org/10.1287/mksc.14.3.G36

Fern, E. F., \& Monroe, K. B. (1996). Effect-size estimates: issues and problems in interpretation. Journal of Consumer Research, 23(2), 89-105. http://dx.doi.org/10.1086/209469

Fitzmaurice, J., \& Comegys, C. (2006). Materialism and social consumption. The Journal of Marketing Theory and Practice, 14(4), 287-299. http://dx.doi.org/10.2753/MTP1069-6679140403

Flouri, E. (1999). An integrated model of consumer materialism: can economic socialization and maternal values predict materialistic attitudes in adolescents? The Journal of Socio-Economics, 28(6), 707-724. http://dx.doi.org/10.1016/S1053-5357(99)00053-0

Froh, J. J., Emmons, R. A., Card, N. A., Bono, G., \& Wilson, J. A. (2011). Gratitude and the reduced costs of materialism in adolescents. Journal of Happiness Studies, 12(2), 289-302. http://dx.doi.org/10.1007/s10902-010-9195-9

Fundo das Nações Unidas para a Infância. (2015). ECA 25 anos estatuto da criança e do adolescente: avanços e desafios para a infância e adolescência no Brasil. Recuperado em http://www.unicef.org/brazil/pt/ECA25anosUNICEF.pdf

Gil, L. A., Kwon, K. N., Good, L. K., \& Johnson, L. W. (2012). Impact of self on attitudes toward luxury brands among teens. Journal of Business Research, 65(10), 1425-1433. http://dx.doi.org/10.1016/j.jbusres.2011.10.008

Goldberg, M. E., Gorn, G. J., Peracchio, L. A., \& Bamossy, G. (2003). Understanding materialism among youth. Journal of Consumer Psychology, 13(3), 278-288. http://dx.doi.org/10.1207/S15327663JCP1303_09

Goldsmith, R. E., \& Clark, R. A. (2012). Materialism, status consumption, and consumer independence. The Journal of Social Psychology, 152(1), 43-60. http://dx.doi.org/10.1080/00224545.2011.555434

Goldsmith, R. E., Moore, M. A., \& Beaudoin, P. (1999). Fashion innovativeness and self-concept: a replication. Journal of Product \& Brand Management, 8(1), 7-18. http://dx.doi.org/10.1108/10610429910257904

Grotts, A. S., \& Johnson, T. W. (2013). Millennial consumers' status consumption of handbags. Journal of Fashion Marketing and Management: An International Journal, 17(3), 280-293. http://dx.doi.org/10.1108/JFMM-10-2011-0067

Gudykunst, W. B. (1993). Toward a theory of effective interpersonal and intergroup communication: an anxiety/uncertainty management (AUM) perspective. In R. L. Wiseman \& J. Koester (Eds.), Intercultural communication competence (pp. 33-71). Newbury Park, CA: Sage.

Handa, M., \& Khare, A. (2013). Gender as a moderator of the relationship between materialism and fashion clothing involvement among Indian youth. International Journal of Consumer Studies, 37(1), 112-120. http://dx.doi.org/10.1111/j.1470-6431.2011.01057.x

Hedges, L. V., \& Olkin, I. (1985). Statistical methods for meta-analysis. Orlando, FL: Academic Press.

Hofstede, G. (1994). The business of international business is culture. International Business Review, 3(1), 1-14. http://dx.doi.org/10.1016/0969-5931(94)90011-6

Hourigan, S. R., \& Bougoure, U.-S. (2012). Towards a better understanding of fashion clothing involvement. Australasian Marketing Journal, 20(2), 127-135. http://dx.doi.org/10.1016/j.ausmj.2011.10.004 
Hunter, J. E., \& Schmidt, F. L. (Eds.). (2004). Methods of meta-analysis: correcting error and bias in research findings. Newbury Park, CA: Sage.

Johnson, T., \& Attmann, J. (2009). Compulsive buying in a product specific context: clothing. Journal of Fashion Marketing and Management: An International Journal, 13(3), 394-405. http://dx.doi.org/10.1108/13612020910974519

Joung, H.-M. (2013). Materialism and clothing post-purchase behaviors. Journal of Consumer Marketing, 30(6), 530-537. http://dx.doi.org/10.1108/JCM-08-2013-0666

Kasser, T., \& Ahuvia, A. (2002). Materialistic values and well-being in business students. European Journal of Social Psychology, 32(1), 137-146. http://dx.doi.org/10.1002/ejsp.85

Kasser, T., \& Ryan, R. M. (1993). A dark side of the American dream: correlates of financial success as a central life aspiration. Journal of Personality and Social Psychology, 65(2), 410-422. http://dx.doi.org/10.1037/0022-3514.65.2.410

Kasser, T., Ryan, R. M., Zax, M., \& Sameroff, A. J. (1995). The relations of maternal and social environments to late adolescents' materialistic and prosocial values. Developmental Psychology, 31(6), 907-914. http://dx.doi.org/10.1037/0012-1649.31.6.907

Kempf, D. S., Laczniak, R. N., \& Smith, R. E. (2006). The effects of gender on processing advertising and product trial information. Marketing Letters, 17(1), 5-16. http://dx.doi.org/10.1007/s11002006-3545-8

Kim, D., \& Jang, S. S. (2014). Symbolic consumption in upscale cafés: examining Korean Gen Y consumers' materialism, conformity, conspicuous tendencies, and functional qualities. Journal of Hospitality \& Tourism Research, 5, 217-233. http://dx.doi.org/10.1177/1096348014525633

Kropp, F., Lavack, A. M., \& Silvera, D. H. (2005). Values and collective self-esteem as predictors of consumer susceptibility to interpersonal influence among university students. International Marketing Review, 22(1), 7-33. http://dx.doi.org/10.1108/02651330510581154

Kruger, D., \& Byker, D. (2009). Evolved foraging psychology underlies sex differences in shopping experiences and behaviors. Journal of Social, Evolutionary, and Cultural Psychology, 3(4), 328342. http://dx.doi.org/10.1037/h0099312

Liao, S.-L., Shen, Y.-C., \& Chu, C.-H. (2009). The effects of sales promotion strategy, product appeal and consumer traits on reminder impulse buying behavior. International Journal of Consumer Studies, 33(3), 274-284. http://dx.doi.org/10.1111/j.1470-6431.2009.00770.x

McCracken, G. (1986). Culture and consumption: a theoretical account of the structure and movement of the cultural meaning of consumer goods. Journal of Consumer Research, 13(1), 71-84. http://dx.doi.org/10.1086/209048

Mueller, A., Mitchell, J. E., Peterson, L. A., Faber, R. J., Steffen, K. J., Crosby, R. D., \& Claes, L. (2011). Depression, materialism, and excessive Internet use in relation to compulsive buying. Comprehensive Psychiatry, 52(4), 420-424. http://dx.doi.org/10.1016/j.comppsych.2010.09.001

Neuner, M., Raab, G., \& Reisch, L. A. (2005). Compulsive buying in maturing consumer societies: an empirical re-inquiry. Journal of Economic Psychology, 26(4), 509-522. http://dx.doi.org/10.1016/j.joep.2004.08.002

O'Cass, A., \& McEwen, H. (2004). Exploring consumer status and conspicuous consumption. Journal of Consumer Behaviour, 4(1), 25-39. http://dx.doi.org/10.1002/cb.155

O'Guinn, T. C., \& Faber, R. J. (1989). Compulsive buying: a phenomenological exploration. Journal of Consumer Research, 16(2), 147-157. http://dx.doi.org/10.1086/209204 
Park, H. J., Rabolt, N. J., \& Jeon, K. S. (2008). Purchasing global luxury brands among young Korean consumers. Journal of Fashion Marketing and Management: An International Journal, 12(2), 244-259. http://dx.doi.org/10.1108/13612020810874917

Richins, M. L. (2004). The material values scale: measurement properties and development of a short form. Journal of Consumer Research, 31(1), 209-219. http://dx.doi.org/10.1086/383436

Richins, M. L., \& Chaplin, L. N. (2015). Material parenting: how the use of goods in parenting fosters materialism in the next generation. Journal of Consumer Research, 41(6), 1333-1357. http://dx.doi.org/10.1086/680087

Richins, M. L., \& Dawson, S. (1992). A consumer values orientation for materialism and its measurement: scale development and validation. Journal of Consumer Research, 19(3), 303-316. http://dx.doi.org/10.1086/209304

Rindfleisch, A., Burroughs, J. E., \& Denton, F. (1997). Family structure, materialism, and compulsive consumption. Journal of Consumer Research, 23(4), 312-325. http://dx.doi.org/10.1086/209486

Rindfleisch, A., Burroughs, J. E., \& Wong, N. (2009). The safety of objects: materialism, existential insecurity, and brand connection. Journal of Consumer Research, 36(1), 1-16. http://dx.doi.org/10.1086/595718

Roberts, J. A., Manolis, C., \& Tanner, J. F. J. (2006). Adolescent autonomy and the impact of family structure on materialism and compulsive buying. The Journal of Marketing Theory and Practice, 14(4), 301-314. http://dx.doi.org/10.2753/MTP1069-6679140404

Roberts, J. A., \& Pirog, S. F., III (2004). Personal goals and their role in consumer behavior: the case of compulsive buying. Journal of Marketing Theory and Practice, 12(3), 61-73. http://dx.doi.org/10.1080/10696679.2004.11658525

Rosenthal, R. (1995). Writing meta-analytic reviews. Psychological Bulletin, 118(2), 183-192. http://dx.doi.org/10.1037//0033-2909.118.2.183

Santos, C. P. dos, \& Fernandes, D. V. (2011). A socialização de consumo e a formação do materialismo entre adolescentes. Revista de Administração Mackenzie, 12(1), 169-203. http://dx.doi.org/10.1590/S1678-69712011000100007

Schmidt, F. L. (1996). Statistical significance testing and cumulative knowledge in psychology: Implications for training of researchers. Psychological Methods, 1(2), 115-129. http://dx.doi.org/10.1037/1082-989X.1.2.115

Tsang, J. A., Carpenter, T. P., Roberts, J. A., Frisch, M. B., \& Carlisle, R. D. (2014). Why are materialists less happy? The role of gratitude and need satisfaction in the relationship between materialism and life satisfaction. Personality and Individual Differences, 64, 62-66. http://dx.doi.org/10.1016/j.paid.2014.02.009

Vega, V., \& Roberts, D. F. (2011). Linkages between materialism and young people's television and advertising exposure in a US sample. Journal of Children and Media, 5(2), 181-193. http://dx.doi.org/10.1080/17482798.2011.558272

Veludo-de-Oliveira, T. M., Ikeda, A. A., \& Santos, R. D. C. (2004). Compra compulsiva e a influência do cartão de crédito. Revista de Administração de Empresas, 44(3), 89-99. http://dx.doi.org/10.1590/S0034-75902004000300007

Wan, W. W., Luk, C. L., Yau, O. H., Alan, C. B., Sin, L. Y., Kwong, K. K., \& Chow, R. P. (2009). Do traditional Chinese cultural values nourish a market for pirated CDs? Journal of Business Ethics, 88(Suppl. 1), 185-196. http://dx.doi.org/10.1007/s10551-008-9821-1 
Ward, S. (1974). Consumer socialization. Journal of Consumer Research, 1(2), 1-14. Recuperado de http://jcr.oxfordjournals.org/content/jcr/1/2/1.full.pdf. http://dx.doi.org/10.1086/208584

Watson, J. J. (2003). The relationship of materialism to spending tendencies, saving, and debt. Journal of Economic Psychology, 24(6), 723-739. http://dx.doi.org/10.1016/j.joep.2003.06.001

Weaver, S. T., Moschis, G. P., \& Davis, T. (2011). Antecedents of materialism and compulsive buying: a life course study in Australia. Australasian Marketing Journal, 19(4), 247-256. http://dx.doi.org/10.1016/j.ausmj.2011.04.007

Wray-Lake, L., Flanagan, C. A., \& Osgood, D. W. (2010). Examining trends in adolescent environmental attitudes, beliefs, and behaviors across three decades. Environment and Behavior, 42(1), 61-85. http://dx.doi.org/10.1177/0013916509335163

Yang, C., De Wang, Y., \& Niu, H. J. (2008). The effects of idolatry and personality traits on impulse buying: an empirical study. International Journal of Management, 25(4), 633-640. Recuperado de https://www.questia.com/library/journal/1P3-1623336551/the-effects-of-idolatry-andpersonality-traits-on

\section{Dados dos Autores}

Wagner Junior Ladeira

Av. Unisinos, 950, Cristo Rei, 93022-000, São Leopoldo, RS, Brasil. E-mail: wjladeira@ gmail.com

Fernando de Oliveira Santini

Av. Unisinos, 950, Cristo Rei, 93022-000, São Leopoldo, RS, Brasil. E-mail: santiniconsultores@ terra.com.br

Clecio Falcão Araujo

Av. Ipiranga, 6681, prédio 50, Porto Alegre, 90619-900, Porto Alegre, RS, Brasil. E-mail: clecioa@ bol.com.br 